\title{
ANNOUNCEMENT \\ Concerning the Brewer Prize Contest, 1948 and 1949
}

Notice is hereby given that after a careful consideration of the several manuscripts submitted for the 1948 Brewer Prize Contest, the Committee unanimously decided that the prize be not awarded this year.

Accordingly, a new Contest shall be held during the year 1949. Manuscripts for this competition should be in the hands of the Secretary on or before June 1, 1949.

Raymond W. Albright, Secretary.

1224 Palm Street

Reading, Penna. 